\title{
Portal Vein Thrombosis
}

National Cancer Institute

\section{Source}

National Cancer Institute. Portal Vein Thrombosis. NCI Thesaurus. Code C78565.

The formation of a blood clot (thrombus) in the portal vein. 